\title{
BMJ Open Frequent outpatient attendance among people on the governmental welfare programme in Japan: assessing both patient and supplier characteristics
}

\author{
Daisuke Nishioka (D) , ${ }^{1,2}$ Junko Saito, ${ }^{3}$ Keiko Ueno, ${ }^{1}$ Naoki Kondo (D) ${ }^{1,2}$
}

To cite: Nishioka D, Saito J, Ueno $\mathrm{K}$, et al. Frequent outpatient attendance among people on the governmental welfare programme in Japan: assessing both patient and supplier characteristics. BMJ Open 2020;10:e038663. doi:10.1136/ bmjopen-2020-038663

- Prepublication history and additional materials for this paper is available online. To view these files, please visit the journal online (http://dx.doi org/10.1136/bmjopen-2020038663).

Received 22 March 2020 Revised 10 August 2020 Accepted 08 September 2020

\section{Check for updates}

(c) Author(s) (or their employer(s)) 2020. Re-use permitted under CC BY-NC. No commercial re-use. See rights and permissions. Published by BMJ.

${ }^{1}$ Department of Health and Social Behavior, Graduate School of Medicine, The University of Tokyo, Bunkyo-ku, Tokyo, Japan

${ }^{2}$ Department of Social Epidemiology and Global Health, Graduate School of Medicine and School of Public Health, Kyoto University, Kyoto, Japan ${ }^{3}$ Behavioral Science Division, Behavioral Sciences and Survivorship Research Group, Center for Public Health Sciences, National Cancer Center Japan, Tokyo, Japan

Correspondence to Dr Naoki Kondo naoki-kondo@umin.ac.jp

\section{ABSTRACT}

Objectives Using linkage data from two municipal public assistance databases and medical assistance claim data, this study aimed to identify characteristics associated with frequent outpatient attendance by people on public assistance, who can access medical care services without copayment in Japan, with simultaneous consideration of supplier factors.

Design We performed a retrospective cohort study. Setting We used secondary data from the public assistance databases of two suburban municipalities in Japan.

Participants The study population included all adults on public assistance in January 2016, who were observed until December 2016. A total of 6016 people was included in the analysis. Among them, 2956 (49.1\%) were men, and $2030(33.7 \%)$ were living alone.

Outcome measure We adopted the definition of frequent outpatient attendance by the Japanese Ministry of Health, Labour and Welfare, visiting the same medical facility 15 times or more in a month for the same health problem. Results of 6016 included people, 139 (2.3\%) were engaged in frequent outpatient attendance. Multiple Poisson regression showed that, as for the individual factors, the adjusted incidence ratio for frequent outpatient attendance was 1.58 (95\% Cl 1.05 to 2.39) for people living alone (vs living with others). As for the suppliers, the adjusted incidence ratio for frequent outpatient attendance was $1.74(95 \% \mathrm{Cl} 1.20$ to 2.52$)$ for private institutions (vs medical corporations). There were no significant associations between frequent outpatient attendance and individual disability certificate or long-term care needs. Conclusions This study suggests that among recipients of public assistance who can access medical services without copayment, social isolation may be associated with frequent outpatient attendance. Private clinics may also be associated with this phenomenon. Interventions to prevent social isolation — by for example, providing health and social care in a more integrated manner-may thus be efficacious in reducing the healthcare demands of socially vulnerable individuals.

\section{BACKGROUND}

Unnecessary frequent outpatient attendance (FOA) has been recognised as problematic because it can affect the quality
Strengths and limitations of this study

- This is the first study to have examined potential factors leading to frequent outpatient attendance among those receive public assistance in Japan.

- We could simultaneously examine the role of both individual-related and supplier-related factors in frequent outpatient attendance.

- Use of existing databases with no missing data of people receiving public assistance enabled us to assess the frequent outpatient attendance of socially vulnerable populations that it might otherwise have been difficult to study using standard social survey techniques.

- Although we used national standardised databases, the variables that we included in our analysis were limited because of data availability; important unmeasured factors such as educational attainments, social relationships, diagnosis, treatment departments, severity of diseases and the extent of medical treatment were not included.

of medical care and threaten the sustainability of healthcare systems. People who use healthcare services frequently, are likely to experience fragmented, uncoordinated and ineffective healthcare, resulting in poor health outcomes. ${ }^{1-5}$ FOA has also been linked to increased economic costs, hospital overcrowding and physicians' stress. ${ }^{16-8}$

Recent studies have revealed that patients' complex biopsychosocial needs may drive their FOA. For example, in terms of biological factors, older age, chronic pain and chronic health conditions such as respiratory problems were associated with patients' FOA. ${ }^{236-20}$ Psychological factors, associated with FOA, include substance abuse, mental illness and loneliness. ${ }^{18}{ }^{20-22}$ Regarding the social determinants of FOA, factors that may be indicative of social isolation such as living alone and being unemployed have also been identified as possible predictors. ${ }^{3613181923}$ FOA could also be influenced by medical care providers, 
that is, the supplier/physician induced demand, which has continuously been discussed as a potential issue that negatively impacts health systems. ${ }^{24-27}$

However, previous studies have not considered determinants from both the patients' and suppliers' sides, simultaneously. To address this deficit this study will examine both patient and supplier characteristics associated with FOA in Japan. Due to the features of the Japanese healthcare system, there are several structures by which physicians could be incentivised to manipulate patients' demand for medical services. ${ }^{28}$ As private practices are motivated to maximise revenue by expanding their business as much as possible, there is the possibility that they will offer services that are either unnecessary and/or unsuitable for some patients. This may be a particular problem in the absence of a gatekeeping system or waiting lists, as patients are free to choose medical facilities regardless of their medical condition, while paying for outpatient services on a fee-for-service basis. ${ }^{28}$ In addition, extra demands are more often made by patients on public assistance, as these patients are fully exempted from copayments for their medical care utilisation. ${ }^{29}$ Nevertheless, to our knowledge, no study until now has examined the potential factors determining FOA among those who are covered by public assistance systems.

Hence, the objective of this study was to explore what individual-level factors were associated with FOA among patients receiving public assistance while simultaneously considering the potential role of healthcare providers in this phenomenon.

\section{METHODS}

\section{Study design}

This retrospective cohort study used linkage data from public assistance databases and medical and long-term care assistance receipt databases administered by each municipality in Japan.

\section{Participants}

Participants included people on public assistance in January 2016 from two suburban municipalities in Japan. These municipalities were chosen conveniently from Tokyo and Osaka. Public assistance is the governmental welfare programme availed by households who are living below the poverty line without any assets. In Japan, approximately $2 \%$ of the population receives public assistance. Households availing public assistance obtain a monthly minimum income protection and are fully exempted from payments for their medical care utilisation. ${ }^{29}$ The participants were observed until December 2016. We excluded the data of people under 20 years, people admitted to a hospital during the study period, and people who stopped receiving public assistance during the study period.

\section{Data sources}

We used the public assistance databases administered by the municipal welfare offices in January 2016 as baseline data; these databases included information on each participant's age, sex, number of family members, household composition, nationality, working status, income including working income, pension and disability pension. These data were collected by staff members in the welfare offices of each municipality when deciding on an application for public assistance, resulting in little missing data. To assess the use of medical services we drew information from the municipalities' medical and long-term care assistance receipt databases. The information in these two databases included the total cost of medical services, the total number of visits to each clinic or hospital in each month with its medical facility codes, and whether these people were certified to receive the public long-term care insurance benefit or not.

Each municipality merged the baseline sociodemographic and healthcare data with information from the public assistance database using individual identification numbers. Because these databases did not include any missing data, all eligible participants were included in this study. The municipal welfare offices agreed to provide anonymised data to the authors via a company that had provided management software of the public assistance database to the welfare offices.

\section{Measurement and variables}

\section{Outcome variable}

We identified the cumulative incidence of FOA during the observation period from the medical assistance receipt data. Although there are no agreed definitions of FOA, we adopted the definition of FOA by the Ministry of Health, Labour and Welfare (MHLW) in Japan: visiting the same medical facility 15 times or more in a month for the same health problem. ${ }^{30}$ This definition is important for policy implication in Japan and also allowed us to exclude patients who required routine outpatient visits such as for haemodialysis. We evaluated the participants' frequent use of the medical facility monthly from the medical assistance receipt database, and determined if participants visited the facility in one or more months during the study period, thereby defining that participant as exhibiting FOA. We could determine patients' FOA because the monthly medical assistance receipt was claimed based on their diagnosis in each medical facility. Outpatient visits included all non-admitted emergency department presentations as well as those to outpatient department of hospitals, outpatient clinics and primary care.

\section{Explanatory variable}

Based on data availability, patients' demographic, socioeconomic and health-related factors were examined in relation to FOA. We also considered physical access to medical facilities. We used information from the public assistance database to identify whether the patient was 
assisted by a disability certificate that included mental, intellectual and physical disability. We also considered the severity of long-term care needs from the long-term care assistance receipt database using information based on the public long-term care insurance system. In the system, there are seven nationally standardised levels of long-term care need (support required levels 1 and 2, and care need levels 1-5)..$^{29}$ People aged 65 years or above who are potentially in need of long-term care, and people aged 40 years or above with the designated diseases can apply for this insurance benefit. Based on the definition of the level, insurers (in most cases municipality governments) assess and certify the use of insurance benefits. The amount of benefit is determined based on the certified level. In this study, we sorted the levels into not certified, certified as support required and certified as care needs.

As demographic factors, we used age (under 65/65 and over), sex (women/men), household composition (living alone or not) and nationality (Japanese or nonJapanese). We dichotomised the age because the policy approach of the Japanese government is differentiated based on age for people on public assistance (ie, people under 65 years old are considered as part of the labour force). Socioeconomic characteristics were assessed with information on employment status (working or not). We coded municipality as a dummy variable to adjust for unmeasured cultural and environmental characteristics of the two municipalities. These variables were extracted from the public assistance databases.

The medical assistance receipt data had unique identification codes for the medical care facilities that patients used. We also obtained access to an external MHLW database with information on the management entity types of medical care facilities. ${ }^{31}$ To identify the characteristics of medical care suppliers, we categorised each hospital/ clinic into one of six groups: national institute, prefectural or public sector, social insurance group, medical corporation, private managed and other. We merged this information with the individual data, identifying the hospitals or clinics that people used most frequently during each month of the study period.

\section{Statistical analysis}

First, we calculated descriptive statistics of the characteristics of all participants and frequent users and summarised their baseline characteristics. Second, we performed an univariable Poisson regression analysis and calculated the crude cumulative incidence ratio (IR) and $95 \%$ CI of each explanatory variable for FOA. Third, we performed multiple Poisson regression analyses to calculate the multivariable-adjusted IR of FOA on each explanatory variable (model 1 ). In model 1 , we used all individual variables: age, sex, living alone or not, working status, disability, long-term care needs, nationality and municipality. In addition, we later performed multiple Poisson regression analyses to examine the effect of both individual-level and supplier factors (model 2). A robust SE estimator was used to calculate $95 \%$ CIs.

Four sensitivity analyses were performed to examine the robustness of our findings. First, we redefined FOA as 10 visits in a month. Second, we performed additional analysis by redefining FOA as 15 or more visits a month for two or more consecutive months in the observational year. Third, we excluded the occurrence of FOA at the baseline month as an outcome to diminish the likelihood of reverse causation, we could exclude patients who started to receive public assistance at the baseline month because of their bad health conditions that required FOA. Fourth, we analysed model 2, using age as a continuous variable.

Statistical analyses were performed using STATA SE V.14.2 (StataCorp).

\section{Patient and public involvement}

Patients and the public were not involved in the present study.

\section{RESULTS}

Data were obtained from 6768 people on public assistance; after excluding non-eligible participants, we included 6016 individuals in the analyses. Among them, $2956(49.1 \%)$ were men, $2030(33.7 \%)$ were living alone and $5081(84.5 \%)$ were unemployed. Regarding medical facility usage, $2870(47.7 \%)$ participants mainly visited hospitals or clinics run by medical corporations, while $1012(18.3 \%)$ participants visited a private institution. During the period from January to December 2016, 139 patients $(2.3 \%)$ were identified as making frequent visits (table 1).

Univariable Poisson regression analysis showed that older age, living alone, unemployment and living in municipality B were significantly associated with FOA (table 2). After adjusting for individual potential confounders, living alone and municipality B continued to be significantly associated with FOA (model 1 in table 2). The model was then adjusted for suppliers' factors (model 2 in table 2). However, this model revealed similar results compared with model 1 . Compared with living with someone, adjusted IR of living alone was 1.58 (95\% CI 1.05 to 2.39) and the adjusted IR of being unemployed was 1.73 (95\% CI 0.86 to 3.48) when compared with being employed. As for supplier factors, private institutions were significantly associated with FOA. Compared with medical corporations, the adjusted IR for private institutions was 1.74 (95\% CI 1.20 to 2.52). The adjusted IR for municipality B was 2.68 (95\% CI 1.91 to 3.74 ) when compared with municipality A. There were no significant associations between FOA and individual disability certificate or long-term care needs.

The results of sensitivity analysis using alternative definitions of FOA showed that living alone and unemployment were associated with FOA (IR 1.25, 95\% CI 1.02 to 1.54 ; IR $1.91,95 \%$ CI 1.30 to 2.81 ; respectively). The 
Table 1 Overall and frequent attenders' characteristics who were on public assistance

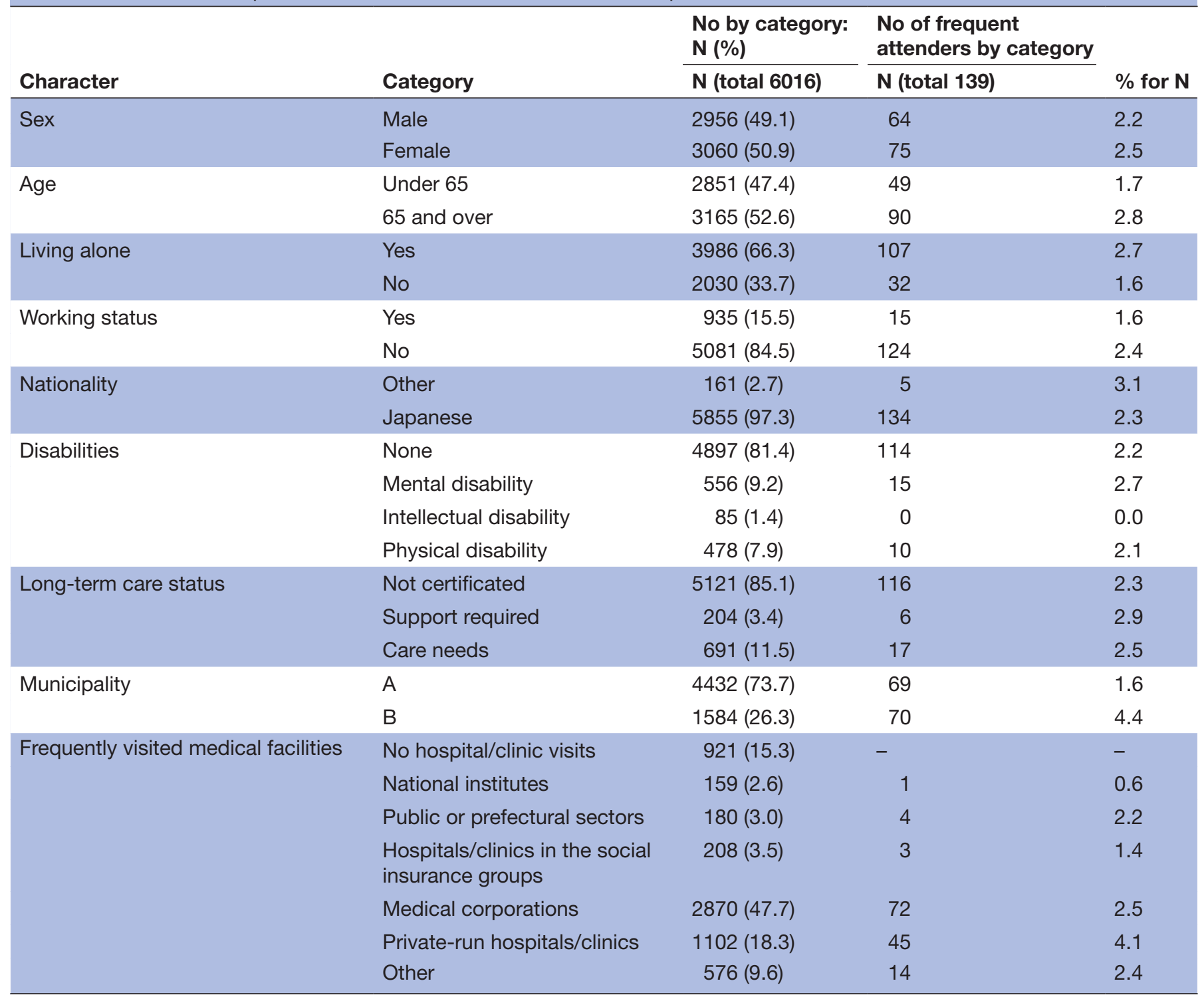

adjusted IR when having a physical disability certificate increased-1.85 (95\% CI 1.44 to 2.38 )—when compared with that of no disabilities. For the suppliers' factor, compared with those visiting medical corporations, those visiting national institutes, public or prefectural sector, and hospitals/clinics with social insurance groups had lower incidences of frequent attendance. Meanwhile, those visiting private hospitals/clinics was 1.18 (95\% CI 0.95 to 1.47 ) when compared with medical corporation. In a further sensitivity analysis, where FOA was defined as making 15 or more medical visits a month for two or more consecutive months in the observational year, living alone and municipality B were still associated with FOA, while the association between going to private hospitals / clinics and FOA became less statistically clear. An additional sensitivity analysis that excluded the occurrence of FOA at the baseline month as the outcome, or using age as a continuous variable, also produced similar results (see online supplemental tables S1-S4).

\section{DISCUSSION}

This study examined whether specific patient and/ or supplier factors were associated with FOA in Japan (defined as visiting the same medical facility 15 times or more in a month for the same health problem). The key findings of this study are, among people on public assistance the incidence of FOA of medical care tended to be greater among those people who were living alone, unemployed, and going to private hospitals or clinics rather than public facilities, independent of other individual and suppliers' factors. This is the first study to have examined potential factors leading to FOA among those receive public assistance in Japan that has simultaneously considered individual-related and supplier-related factors.

\section{Findings in context}

Our findings of the association between living alone and being unemployed with FOA are consistent with the 
Table 2 Incidence ratios (IRs) and 95\% Cls for experiencing frequent outpatient attendance by individual and suppliers' characteristics: results of crude and multiple Poisson regression

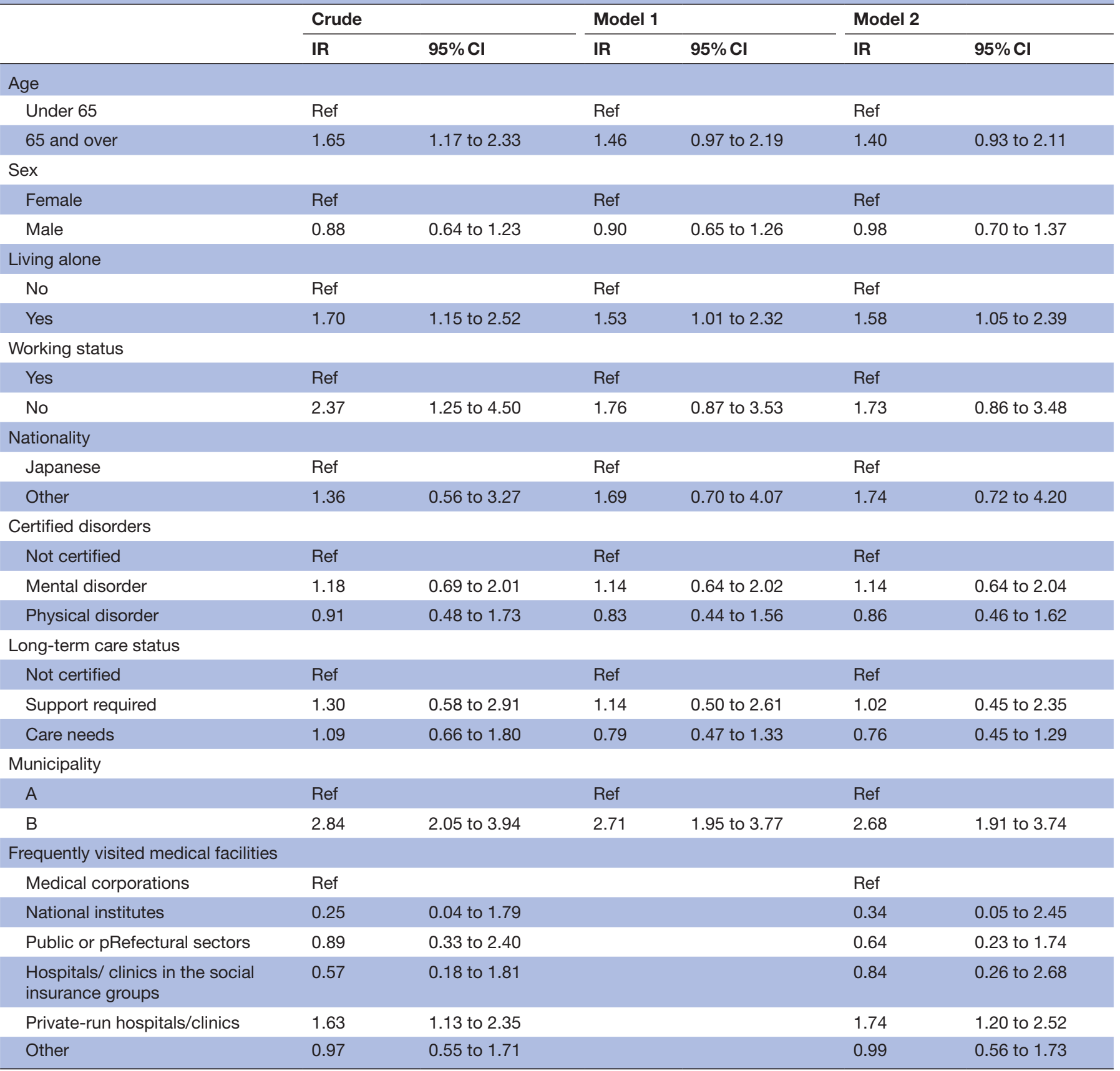

A total of 6016 recipients were included, 139 (2.3\%) were engaged in frequent outpatient attendance. The pseudo R square was 0.041 in model 1 and 0.050 in model 2. In model 1, we used all individual variables: age, sex, living alone or not,working status, nationality, disabilities, long-term care status and municipality. In model 2, we examined the effect of both individual factors and supplier factors.

results from a recent study that found a possible association between social isolation, being single, and unemployment with FOA in both the general and homeless population in Canada. ${ }^{23}$ Thus, our study adds the new evidence that social isolation may also be important for FOA among those on public assistance in Japan. Living alone and/or being unemployed may be linked to having fewer resources to deal with their health problems and concerns regarding daily life. Patients living alone might also be at an increased risk of feeling lonely. ${ }^{32}$ In terms of the present study this may be important as loneliness may act as a spur for individuals, lacking the opportunity for social participation/communication, to make frequent visits to healthcare facilities in search of social interaction. Taube et al found, for example, that loneliness accelerated patients' use of outpatient medical services in Sweden. ${ }^{34}$

Our results also showed that FOA was more likely to occur in relation to privately run hospitals and clinics. This may be because privately run hospitals and clinics 
are the most common types of medical care facilities in Japan. ${ }^{35}$ Further, patients wish to go to nearby hospitals or clinics; those who have chronic medical issues and require frequent medical care may be more likely to visit clinics nearby. This result also provides support for the notion of supplier-induced demand ${ }^{24}$ : compared with managers of public hospitals, individuals running private hospitals/ clinics, may be more inclined to recommend that patients visit their hospital or clinic more often, in order to maximise revenue. However, we did not specifically evaluate the role of supplier-induced demand and its impact on FOA, as this was outside the scope of the present study.

\section{Practice and policy implications}

The results of this study have important policy implications. In particular, the formulation and introduction of measures that prevent/reduce social isolation and the loss of community among socially vulnerable populations, including people on public assistance welfare support, may be important for reducing FOA. For example, there is some evidence that a community-based intervention that provides volunteers to accompany patients with social care needs to hospital may help prevent FOA. ${ }^{36}$ Another potentially effective approach is to address patients' isolation, poverty, and other social difficulties in hospitals and clinics, based on partnerships between medical care facilities and other public and private welfare and community development services. ${ }^{37} 38$ Maughan et al found for instance, that 'social prescribing', by the relevant action framework had a positive effect on reducing medical care utilisation in the UK. ${ }^{39}$

\section{Strengths and limitations}

An important strength of this study is that by using existing standardised databases of people receiving public assistance, we could assess the FOA of socially vulnerable populations that it might otherwise have been difficult to study using standard social survey techniques. Another strength is that we could simultaneously examine the role of both individual-related and supplier-related factors in FOA. Although we only evaluated the types of suppliers as a fixed-effects variable, we could control overall characteristics between facilities. Nonetheless, this study has several limitations that should be mentioned. First, although we have made use of longitudinal data, there is still the possibility that reverse causation might have been a factor in the observed associations. For instance, patients who frequently attend outpatient medical services may have had severe, complex illnesses that have required a great deal of medical care for a long time, which resulted in them losing their partners and/or jobs before the cohort started. However, the robust results of the sensitivity analysis, which excluded the outcome from the baseline month, suggested that reverse causation was unlikely to explain our results. Second, generalisability is limited, because this study covered only two convenient municipalities that did not represent Japanese municipalities. Third, the variables that we included in our analysis were limited because of data availability; important unmeasured factors such as educational attainments, social relationships, diagnosis, treatment departments, severity of diseases and the extent of medical treatment were not included. Finally, we used the standard Japanese definition of FOA, but it should be acknowledged that for some service users, FOA may occur as a result of medical necessity.

\section{CONCLUSION}

The findings of this study suggest that among people receiving public assistance, factors associated with social isolation, such as living alone and being unemployed, may increase the likelihood of FOA, and that this is more likely to occur at private clinics. Interventions that are designed to provide health and social care in a more integrated manner and that thus might prevent/reduce social isolation may be effective in reducing healthcare demands. Further investigation of this phenomenon using more detailed information such as the severity of health conditions and broader socioeconomic factors is now warranted.

Twitter Daisuke Nishioka @DiceNish

Acknowledgements We would like to thank Hideki Hashimoto and Andrew Stickley for their helpful comments and support for the analysis and data interpretation.

Contributors DN, JS, KU and NK conceptualised and designed the study. DN analysed the data and prepared the manuscript. NK finalised the manuscript. All authors read and approved the final manuscript.

Funding This study was supported by Japan Society for the Promotion of Science KAKENHI grants (grant number: 17K19793, 18H04071); the Japanese Ministry of Health, Labour and Welfare (grant number: N/A); and Kitanihon Computer Service. (KITACOM) (grant number: N/A), who provided the data used. This study program was selected for the research promotion award and funded by the Japan Medical Association (grant number: N/A). The research funding bodies had no discretion and involvement in our study protocol, analysis, interpretation of the results, or the submission of this manuscript.

Competing interests NK conducted collaborative research with Kitanihon Computer Service Co. Ltd. (KITACOM) that provided the data used in the present paper. NK received a research fund and a scholarship donation from KITACOM.

Patient consent for publication Not required.

Ethics approval This study protocol was approved by the Ethics Committee of the Graduate School of Medicine of the University of Tokyo (Approval No: 11503).

Provenance and peer review Not commissioned; externally peer reviewed.

Data availability statement The data that support the findings of this study are available from participated municipalities in Japan but restrictions apply to the availability of these data, which were used under license for the current study, and so are not publicly available. Data are, however, available from the authors on reasonable request and with permission of the municipalities.

Supplemental material This content has been supplied by the author(s). It has not been vetted by BMJ Publishing Group Limited (BMJ) and may not have been peer-reviewed. Any opinions or recommendations discussed are solely those of the author(s) and are not endorsed by BMJ. BMJ disclaims all liability and responsibility arising from any reliance placed on the content. Where the content includes any translated material, BMJ does not warrant the accuracy and reliability of the translations (including but not limited to local regulations, clinical guidelines, terminology, drug names and drug dosages), and is not responsible for any error and/or omissions arising from translation and adaptation or otherwise.

Open access This is an open access article distributed in accordance with the Creative Commons Attribution Non Commercial (CC BY-NC 4.0) license, which 
permits others to distribute, remix, adapt, build upon this work non-commercially, and license their derivative works on different terms, provided the original work is properly cited, appropriate credit is given, any changes made indicated, and the use is non-commercial. See: http://creativecommons.org/licenses/by-nc/4.0/.

\section{ORCID iDs}

Daisuke Nishioka http://orcid.org/0000-0002-3116-1195

Naoki Kondo http://orcid.org/0000-0002-6425-6844

\section{REFERENCES}

1 Cook LJ, Knight S, Junkins EP, et al. Repeat patients to the emergency department in a statewide database. Acad Emerg Med 2004;11:256-63.

2 Hoot NR, Aronsky D. Systematic review of emergency department crowding: causes, effects, and solutions. Ann Emerg Med 2008;52:126-36.

3 Krieg C, Hudon C, Chouinard M-C, et al. Individual predictors of frequent emergency department use: a scoping review. BMC Health Serv Res 2016;16:594.

4 Malone RE. Heavy users of emergency services: social construction of a policy problem. Soc Sci Med 1995;40:469-77.

5 Schoen C, Osborn R, Squires D, et al. New 2011 survey of patients with complex care needs in eleven countries finds that care is often poorly coordinated. Health Aff 2011;30:2437-48.

6 Cruwys T, Wakefield JRH, Sani F, et al. Social isolation predicts frequent attendance in primary care. Ann Behav Med 2018;52:817-29.

7 LaCalle E, Rabin E. Frequent users of emergency departments: the myths, the data, and the policy implications. Ann Emerg Med 2010;56:42-8.

8 Sandoval E, Smith S, Walter J, et al. A comparison of frequent and infrequent visitors to an urban emergency department. J Emerg Med 2010;38:115-21.

9 Alghanim SA, Alomar BA. Frequent use of emergency departments in Saudi public hospitals: implications for primary health care services. Asia Pac J Public Health 2015;27:NP2521-30.

10 Althaus F, Paroz S, Hugli O, et al. Effectiveness of interventions targeting frequent users of emergency departments: a systematic review. Ann Emerg Med 2011;58:e42:41-52.

11 Doupe MB, Palatnick W, Day S, et al. Frequent users of emergency departments: developing standard definitions and defining prominent risk factors. Ann Emerg Med 2012;60:24-32.

12 Dufour I, Chouinard M-C, Dubuc N, et al. Factors associated with frequent use of emergency-department services in a geriatric population: a systematic review. BMC Geriatr 2019;19:185.

13 Hand C, McColl MA, Birtwhistle R, et al. Social isolation in older adults who are frequent users of primary care services. Can Fam Physician 2014;60:e322:e4-9.

14 Hansagi $\mathrm{H}$, Allebeck $\mathrm{P}$, Edhag $\mathrm{O}$, et al. Frequency of emergency department attendances as a predictor of mortality: nine-year follow-up of a population-based cohort. J Public Health Med 1990;12:39-44.

15 Hansagi $\mathrm{H}$, Olsson M, Sjöberg S, et al. Frequent use of the hospital emergency department is indicative of high use of other health care services. Ann Emerg Med 2001;37:561-7.

16 Hunt KA, Weber EJ, Showstack JA, et al. Characteristics of frequent users of emergency departments. Ann Emerg Med 2006;48:1-8.

17 Paul P, Heng BH, Seow E, et al. Predictors of frequent attenders of emergency department at an acute General Hospital in Singapore. Emerg Med J 2010;27:843-8.

18 Soril LJJ, Leggett LE, Lorenzetti DL, et al. Characteristics of frequent users of the emergency department in the general adult population: a systematic review of international healthcare systems. Health Policy 2016;120:452-61.

19 van Tiel S, Rood PPM, Bertoli-Avella AM, et al. Systematic review of frequent users of emergency departments in non-US hospitals: state of the art. Eur J Emerg Med 2015;22:306-15.

20 Mandelberg JH, Kuhn RE, Kohn MA. Epidemiologic analysis of an urban, public emergency department's frequent users. Acad Emerg Med 2000;7:637-46.

21 Agarwal G, Lee J, McLeod B, et al. Social factors in frequent callers: a description of isolation, poverty and quality of life in those calling emergency medical services frequently. BMC Public Health 2019;19:684.

22 Wang $\mathrm{H}$, Zhao E, Fleming J, et al. Is loneliness associated with increased health and social care utilisation in the oldest old? Findings from a population-based longitudinal study. BMJ Open 2019;9:e024645

23 Chambers C, Chiu S, Katic M, et al. High utilizers of emergency health services in a population-based cohort of homeless adults. Am J Public Health 2013;103(Suppl 2):S302-10.

24 Evans RG. Supplier-induced demand: some empirical evidence and implications. The economics of health and medical care. Springer 1974:162-73

25 Johnson EM. Physician-induced demand. Cambridge, MA: Elsevier, 2014: 77-83.

26 McGuire TG, Pauly MV. Physician response to fee changes with multiple payers. J Health Econ 1991;10:385-410.

27 van Dijk CE, van den Berg B, Verheij RA, et al. Moral hazard and supplier-induced demand: empirical evidence in general practice. Health Econ 2013;22:340-52.

28 Sekimoto M, li M. Supplier-induced demand for chronic disease care in Japan: multilevel analysis of the association between physician density and physician-patient encounter frequency. Value Health Reg Issues 2015;6:103-10.

29 Sakamoto H, Rahman M, Nomura S, et al.. Japan health system review [online]. World Health Organization. Regional Office for SouthEast Asia, 2018. Available: https://apps.who.int/iris/handle/10665/ 259941 [Accessed 21 Jul 2020].

30 The Ministry of Health, Labour, and Welfare. Appropriate medical assistance and health management for people on public assistance (in Japanese), 2017.

31 The Ministry of Health, Labour and Welfare. Explanation of terms: types and categorization of health care Institutes (in Japanese), 2013.

32 Chen Y, Hicks A, While AE. Loneliness and social support of older people living alone in a county of Shanghai, China. Health Soc Care Community 2014;22:429-38.

33 Jennifer Yeh S-C, Lo SKLiving alone, social support, and feeling Lonely among the elderly. Soc Behav Pers 2004;32:129-38.

34 Taube E, Kristensson J, Sandberg M, et al. Loneliness and health care consumption among older people. Scand J Caring Sci 2015;29:435-43.

35 The Ministry of Health, Labour and Welfare. Overview of the medical facilities survey and hospital reports (in Japanese) [online], 2006. Available: https://www.mhlw.go.jp/toukei/saikin/hw/iryosd/16/ [Accessed 21 Jul 2020]

36 Seaberg D, Elseroad S, Dumas M, et al. Patient navigation for patients frequently visiting the emergency department: a randomized, controlled trial. Acad Emerg Med 2017;24:1327-33.

37 Hudon C, Chouinard M-C, Dubois M-F, et al. Case management in primary care for frequent users of health care services: a mixed methods study. Ann Fam Med 2018;16:232-9.

38 Bickerdike L, Booth A, Wilson PM, et al. Social prescribing: less rhetoric and more reality. A systematic review of the evidence. BMJ Open 2017;7:e013384.

39 Maughan DL, Patel A, Parveen T, et al. Primary-care-based social prescribing for mental health: an analysis of financial and environmental sustainability. Prim Health Care Res Dev 2016;17:114-21. 